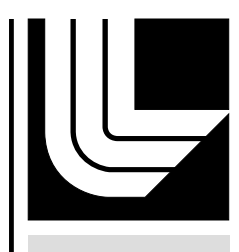

LAWRENCE LIVERMORE N A TIO NAL LABORATORY

\title{
LLNL-TH-646473
}

\section{Noise Exposure Summary And Comparitive Analyses}

P. A. Bumala

November 19, 2013 
This document was prepared as an account of work sponsored by an agency of the United States government. Neither the United States government nor Lawrence Livermore National Security, LLC, nor any of their employees makes any warranty, expressed or implied, or assumes any legal liability or responsibility for the accuracy, completeness, or usefulness of any information, apparatus, product, or process disclosed, or represents that its use would not infringe privately owned rights. Reference herein to any specific commercial product, process, or service by trade name, trademark, manufacturer, or otherwise does not necessarily constitute or imply its endorsement, recommendation, or favoring by the United States government or Lawrence Livermore National Security, LLC. The views and opinions of authors expressed herein do not necessarily state or reflect those of the United States government or Lawrence Livermore National Security, LLC, and shall not be used for advertising or product endorsement purposes.

This work performed under the auspices of the U.S. Department of Energy by Lawrence Livermore National Laboratory under Contract DE-AC52-07NA27344. 


\title{
Facility Maintenance Worker
}

\author{
Noise Exposure Assessment \\ Summary \\ And \\ Comparative Analysis
}

Submitted by

\section{Philip A. Bumala, CIH}

\section{Submitted as a Draft Cap Stone in Partial Fulfillment of the Requirements \\ For the \\ Master of Science \\ Public Health Degree}

Tulane School of Public Health

And

Tropical Medicine 


\section{Table of Contents}

\section{Section Topic}

II Summary of Findings

III Noise Dosimetry Approach

IV Methods

$\begin{array}{lll}\text { V Results Discussion } & 12\end{array}$

VI Conclusions / Recommendations 13

$\begin{array}{lll}\text { VII Table of Acronyms } & 14\end{array}$

\section{Tables}

Table 1: Summary of LLNL MUSD Data Quality Objective Process

Table 2: Comparative Noise Dosimetry Summary

Figures

Figure $1 \quad$ Number of Samples per O\&M Task

Figure 2 LLNL Dosimetry Data (Highest to Lowest)

Figure 3 Noise Dosimetry Average And Range 


\section{Attachments}

MUSD Dosimetry data

Dosimetry Statistics

\section{Appendices}

$1 \quad$ Noise Dosimetry Record (Example) 


\section{Introduction / Summary of Findings / Background}

\section{Introduction}

This paper summarizes and compares facility Operations and Maintenance (O\&M) noise Dosimetry data to industry wide construction data. Dosimetry data has been compiled from a noise exposure assessment at a DOE national research facility Maintenance, Utilities, and Service Department (MUSD). This facility is the Lawrence Livermore National Laboratory (LLNL). The laboratory consists of ten O\&M craft and trade shops responsible for a fifty year old infrastructure including over 300 buildings, and a worker population of approximately 7,000. The facility includes an extensive variety of noise generating activities throughout a one square mile site.

\section{Summary of Findings}

Seventy-nine Dosimetry assessments were completed within LLNL's Maintenance, Utilities, and Service Department including 19 craft and trade Similar Exposure Groups (SEGs). The assessments represented normal O\&M operations similar to construction activities. The range of Dosimetry values was 71.5 to 94.6 $\mathrm{dB}(\mathrm{A})$. $21.5 \%$ of the values exceeded the ACGIH TLV of $85 \mathrm{~dB}(\mathrm{~A})$.

Those MUSD SEGs subject to noise exposures in excess of $85 \mathrm{~dB}(\mathrm{~A})$ were:
1. Carpenters
4. Jack Hammering
2. Demolition Workers
5. Landscaping, and
3. Heavy Equipment Operations
6. Machine Maintenance

None of the SEGs were found to have been exposed to an impulse noise level of $140 \mathrm{~dB}(\mathrm{~A})$.

\section{Comparative Analysis}

Overall LLNL MUSD Dosimetry values appear to be similar to recent Construction Industry exposure data including specific SEGs such as, Carpenters, Electricians, Equipment Operators, and Sheet Metal workers as shown in Table 2, Comparative Noise Dosimetry Summary. 


\section{Background}

Every year, approximately 30 million people in the United States are occupationally exposed to hazardous noise. Over half a million US Construction and Maintenance workers are exposed to hazardous levels of noise similar to that discussed in recent occupational health and safety literature ${ }^{1}$. The reduction of hazardous noise exposures can be difficult when dealing with transient work forces, multiple noise sources, and an OSHA regulatory environment that falls short of encouraging hearing loss prevention to the extent needed. For example, Timothy Rink, PhD, of the National Hearing Conservation Association (NHCA) in a letter dated March 16, 2011 asserts the following:

The United States currently lags behind many industrialized nations in the implementation of effective noise controls. There appears to be a misconception that 29 CFR 1910.95 provides reasonable intervention to adequately protect noise exposed workers. In fact, these very interventions are based upon dated and often discredited methods for assessing the risk of permanent hearing damage from exposure to noxious levels of noise on the job. ${ }^{2}$

Facilities covered by the general industry noise standard are required to institute Hearing Conservation Programs (HCPs) to prevent noise-induced hearing loss (NIHL) if the 8 hour time weighted average noise levels are at or above $85 \mathrm{~dB}(\mathrm{~A})$. However, the construction industry, as noted above, has historically lagged behind the General Industry requirements to implement Hearing Conservation Programs (HCPs) despite excessive noise exposures ${ }^{3}$. 


\section{Noise Dosimetry Assessment Approach}

\section{Introduction}

This study design has been prepared in accordance with the following protocols:

- U.S. Department of Labor, Occupational Safety and Health Administration, OSHA Technical Manual, Chapter 5, Noise and Hearing Conservation, TED 01-00-015 [TED 1-0.15A] ${ }^{4,}$, and

- Environmental Protection Agency, Guidance for Quality Assurance Project Plans, EPA QA/G- $5^{5}$.

The purpose of this assessment approach is to provide a clear understanding of the data quality objectives, sampling strategy, analytical methods and data analysis methods for the project.

\section{Problem Definition}

LLNL'S Health Services Department has identified a number of Standard Threshold Shifts (STS) amongst MUSD employees. In addition, a note has been made indicating a need to more thoroughly assess noise exposure data for the MUSD similar exposure groups (SEGs). Data has been collected to answer the following study questions:

a) To what noise levels are MUSD employees exposed relative to shop activities and noise sources?

b) Are MUSD employees exposed to noise levels greater than the 8-hour ACGIH TLV exposure limit of $85 \mathrm{~dB}(\mathrm{~A})$ ?

c) Are MUSD employees exposed to noise equal to or greater than an instantaneous (peak) level of $140 \mathrm{~dB}(\mathrm{C})$ ?

d) Are the noise exposures to MUSD employee's variable from day-to-day?

\section{Quality Objectives and Criteria for Measurement Data}

The data quality objective (DQO) process as summarized in Table 1, was used as a systematic process for planning data collection activities to ensure that the right type, quality, and quantity of data are collected to satisfy users' needs. The system provides quantitative and qualitative measures that help determine whether the data is scientifically defensible for use in drawing conclusions to answer the study questions ${ }^{6}$.

\section{Measurement Performance Criteria}


The following data quality indicators have been used to determine whether the data collected for this project meet the DQO's:

Precision - A measure of agreement among repeated measures of the same property under identical, or substantially similar conditions. This was assured by use of instrumentation of the same make and model, and identical calibration processes for both the Type II Sound Level Meter (SLM) and the Quest NoisePro dosimeters.

Accuracy - A measure of overall agreement of a measurement to a known value. According to the calibration procedure, the noise dosimeters are calibrated to the precision of $\pm-0.8 \mathrm{~dB}$ (Accuracy of Quest NoisePro ${ }^{\mathrm{TM}} \mathrm{ND}: \pm 0.5 \mathrm{~dB}$, plus accuracy of QC-20- $\pm 0.3 \mathrm{~dB}$ ) and the sound level meters are calibrated to the precision of $\pm 0.8 \mathrm{~dB}$.

Realism - The extent to which the measured data represents the actual worker activity normally conducted. Verification of normal activities planned for Dosimetry was conducted by observing routine worker activities, and interviewing workers. 


\section{Table 1: Summary of Data Quality Objective Process}

1. State the Problem

2. Identify the Decision

3. Identify inputs to the Decision

4. Define the Study Boundaries

5. Develop a decision rule

6. Specify Limit of Decision Errors

7. Optimize the Design for Obtaining Data
The Noise SME has identified a problem that there have been a number of standard threshold shifts (STS) amongst the MUSD employees.

Are employees experiencing noise TWAs greater than the ACGIH TLV exposure limit for an 8-hour shift?

1. Use of 3M Noise Indicator during various operations to determine hazardous situations.

2. Use sound level meters to identify sources of contributing noise.

3. Implement noise Dosimetry to assess worker exposures for different work tasks performed by various MUSD shops.

The dosimetry assessment has been limited to the work performed by employees of MUSD. Dosimetry data will be compared to Construction wide data.

Employee noise exposure is at or above a Time Weighted Average of 85 $\mathrm{dB}(\mathrm{A})$.

The probability of making an incorrect decision has been limited to $5 \%$.

Noise monitoring will only be performed for work tasks of a high noise level hazard, as indicated by the $3 \mathrm{M}$ Noise indicators.

\section{Personnel Training and Qualifications}

All personnel performing data collection were trained in the use of the SLMs and dosimeters. At the beginning of the project, all field personnel received refresher training on the procedures and processes defined in this plan. If new field personnel were introduced to the project, they received similar training before they were allowed to collect samples unsupervised. 


\section{IV .Methods}

\subsection{Sampling Strategy and Methods Requirements}

\subsubsection{Pre-Planning}

Prior to sample data collection, MUSD work orders describing field activities were organized into appropriate tasks with associated documentation of hazard evaluations. Industrial Hygienists utilized O\&M work orders to determine field activities, location of sampling, and sample maps for data collection. Industrial Hygienists attended MUSD Shops' Plan of the Day (POD) meetings to build rapport with MUSD personnel, and receive briefings of daily scope of work.

\subsubsection{Instrumentation}

All sampling equipment were inspected and tested before use in the field. The equipment was reinspected after each use. Any damaged or malfunctioning equipment was tagged and removed from service until it was properly repaired and new measurements were obtained. Equipment is routinely inspected and calibrated by its manufacturer annually.

Noise indicator - used as a screening device to determine which MUSD activities may require additional monitoring with a noise dosimeter. The noise indicator is manufactured by $3 \mathrm{M}^{\mathrm{TM}}$ and does not require calibration. The indicator will blink green when noise is below the LLNL exposure limit of 85 decibels and blink red above the exposure limit $( \pm 3 \mathrm{~dB}(\mathrm{~A})$. The Noise Indicator provided easy, durable noise level detection by alerting users to potentially dangerous noise levels and helping identify areas where hearing protection may need to be worn.

Sound level meter - a Quest Model 2200 Sound Level Meter (SLM) was used to accompany the noise indicator to spot-check noise levels while observing various work tasks. The sound level meter was calibrated at the beginning and end of each shift in accordance with the OSHA Technical Manual (OTM). A secondary standard calibration device was used.

Noise dosimeter - Quest Technologies Noise-Pro Dosimeters were used to determine employee noise dose over a full 8-hour work shift. The noise dosimeter was calibrated at the beginning and end of each shift in accordance with the OTM. A primary standard calibration device was used to verify calibration. 
Octave band analyzer (OBA, QC10 Model 2700) - was made available to help determine the adequacy of various types of frequency-dependent noise controls. The OBA was utilized under specific circumstances when measuring the amount of attenuation (how much sound is weakened) for a specific task. The OBA was calibrated to a primary standard at the beginning and end of each shift in accordance with the OTM.

\subsubsection{Sampling}

Field forms were used by the field Industrial Hygienist throughout the sampling process (Appendix 2, 605 - IH Noise Dosimetry Record, and 606 IH Sound Level / Octave Band Analysis Record). These forms were used during calibrations, and specific field notations taken throughout sampling per LLNL's Industrial Hygiene Field Operations Manual. A water-proof pen was used for appropriate notations during sampling and a tape measure was carried to appropriately map out high decibel areas and identify the $85 \mathrm{~dB}(\mathrm{~A})$ line, or noise impact radius, of each piece of loud equipment or tool. This was done in order to appropriately assess noise severities with a sound level meter at varying distances.

Personal Protective Equipment (PPE) was required by IH field personnel due to the varying work locations of the MUSD personnel. Required minimum PPE included: safety shoes, safety glasses with side shields, and hearing protection. A hard hat was worn according to MUSD requirements for specific work areas/tasks.

\subsubsection{Data Input/Documentation}

Personal data results were entered into an industrial hygiene database by Similar Exposure Groups (SEGs) in terms of equivalent level $\left(\mathrm{L}_{\mathrm{eq}}\right)$, average level $\left(\mathrm{L}_{\mathrm{avg}}\right)$, peak level $\left(\mathrm{L}_{\mathrm{pk}}\right)$, percent dose $(\%$ Dose); and control measures). Area measurements were maintained in a spreadsheet to document quality and progress of work. Photographs, diagrams, floor plans, etc. were used in conjunction with field forms to document noise levels.

\subsubsection{Sampling System Failure}

If an event occured that resulted in equipment failure, delays sample processing, affects holding times, delays work or impacts data quality, the event was documented.

\subsubsection{Instrument/Equipment Testing, Inspection and Maintenance Requirements}

All instrument and equipment testing was performed in accordance with the current LLNL Industrial Hygiene Instrumentation Calibration Procedures. 


\section{Results Discussion}

\section{LLNL MUSD Dosimetry}

Seventy nine MUSD Dosimetry assessments were conducted over a one year period representing worker noise exposures during nineteen activities related to facility operation and maintenance (O\&M) as shown in Figure 1 below. All of the MUSD Dosimetry data are tabulated in Attachment 1.

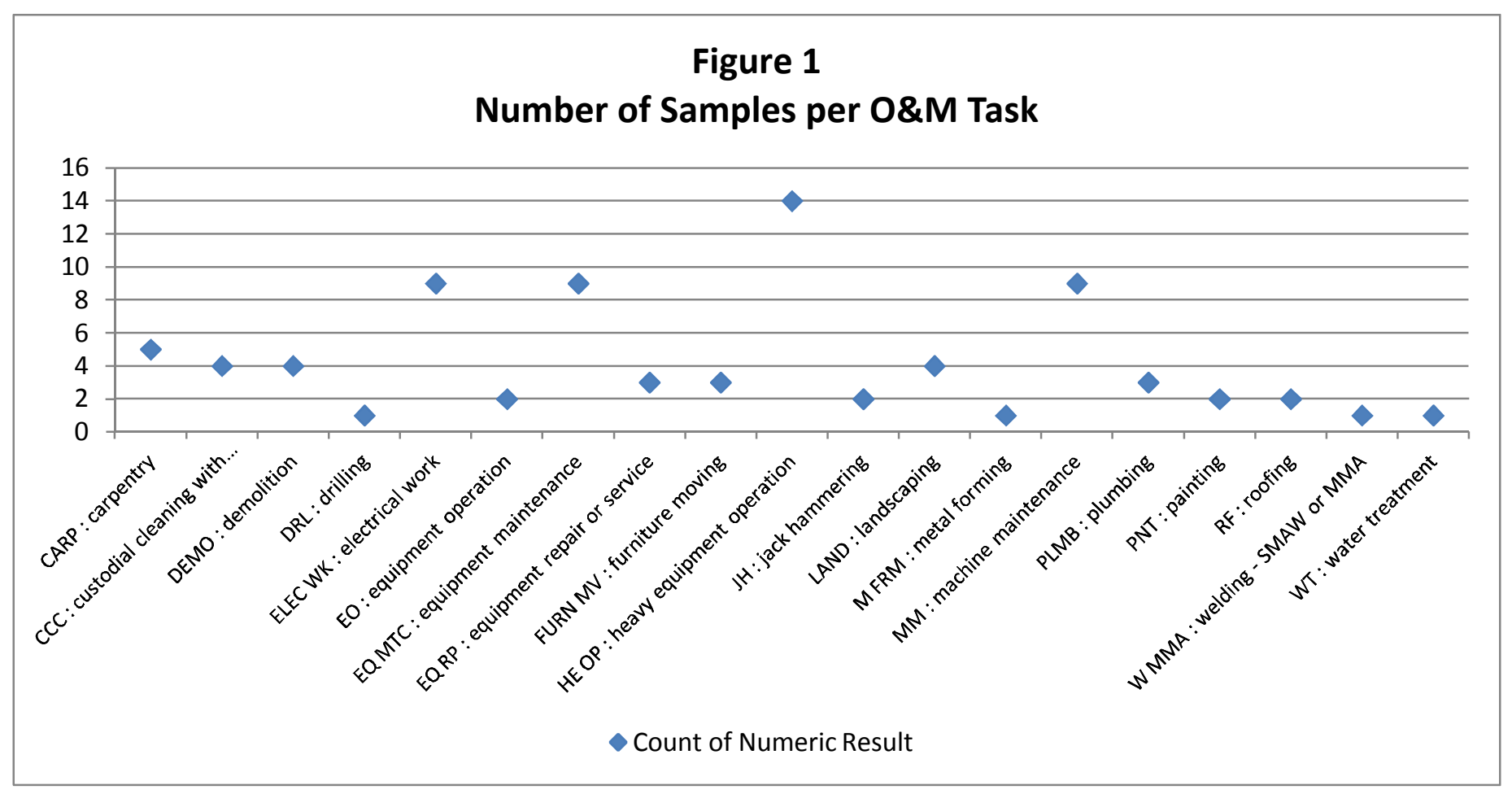


The Dosimetry data ranged from a minimum of 71.5 to a maximum of $94.6 \mathrm{~dB}(\mathrm{~A})$ as summarized in Figure 2 and 3. Twenty-one point five (21.5) percent of the data exceeded the ACGIH TLV of $85 \mathrm{~dB}(\mathrm{~A})$ as shown in Section 3, Dosimetry Descriptive Statistics.

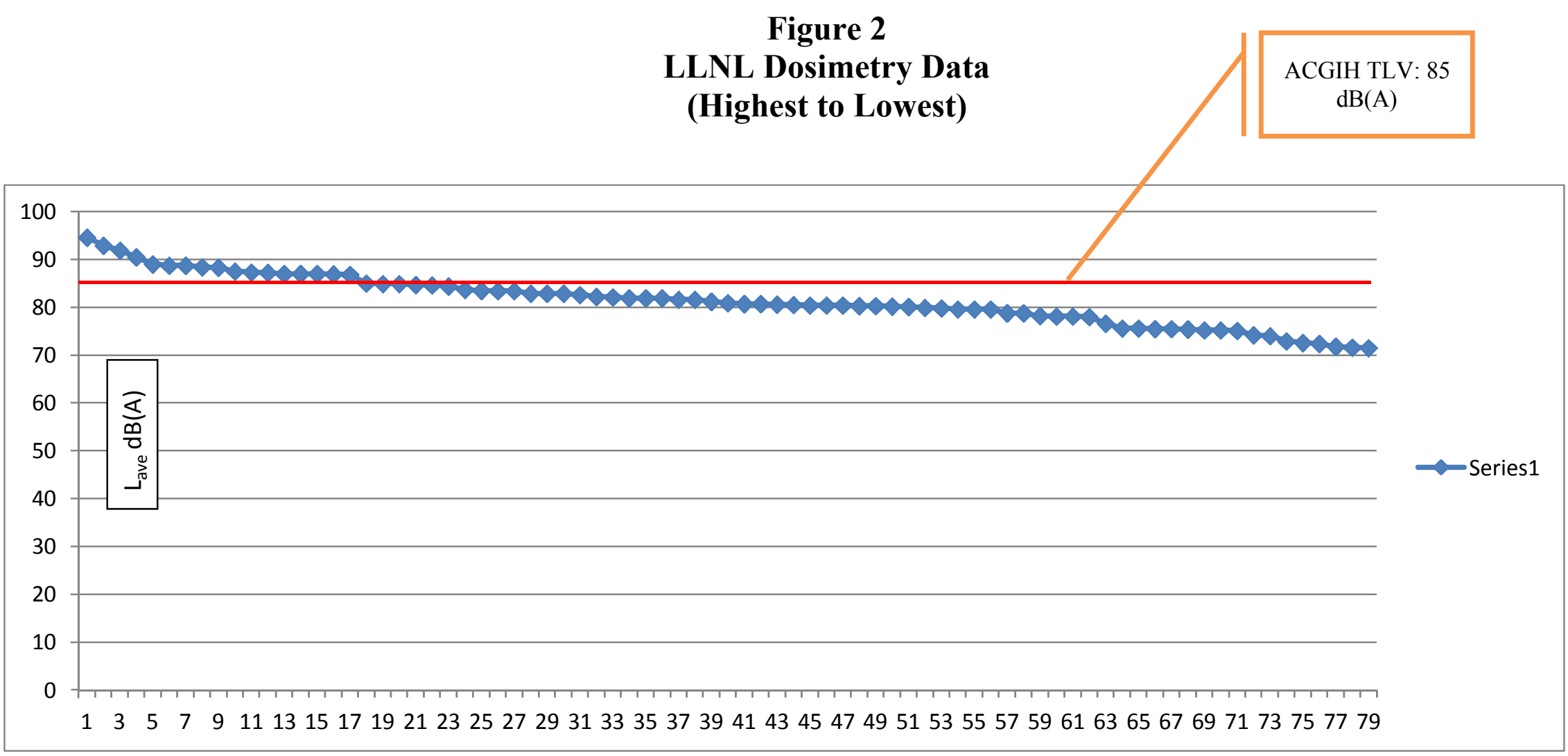

Sample Number 


\section{Figure 3}

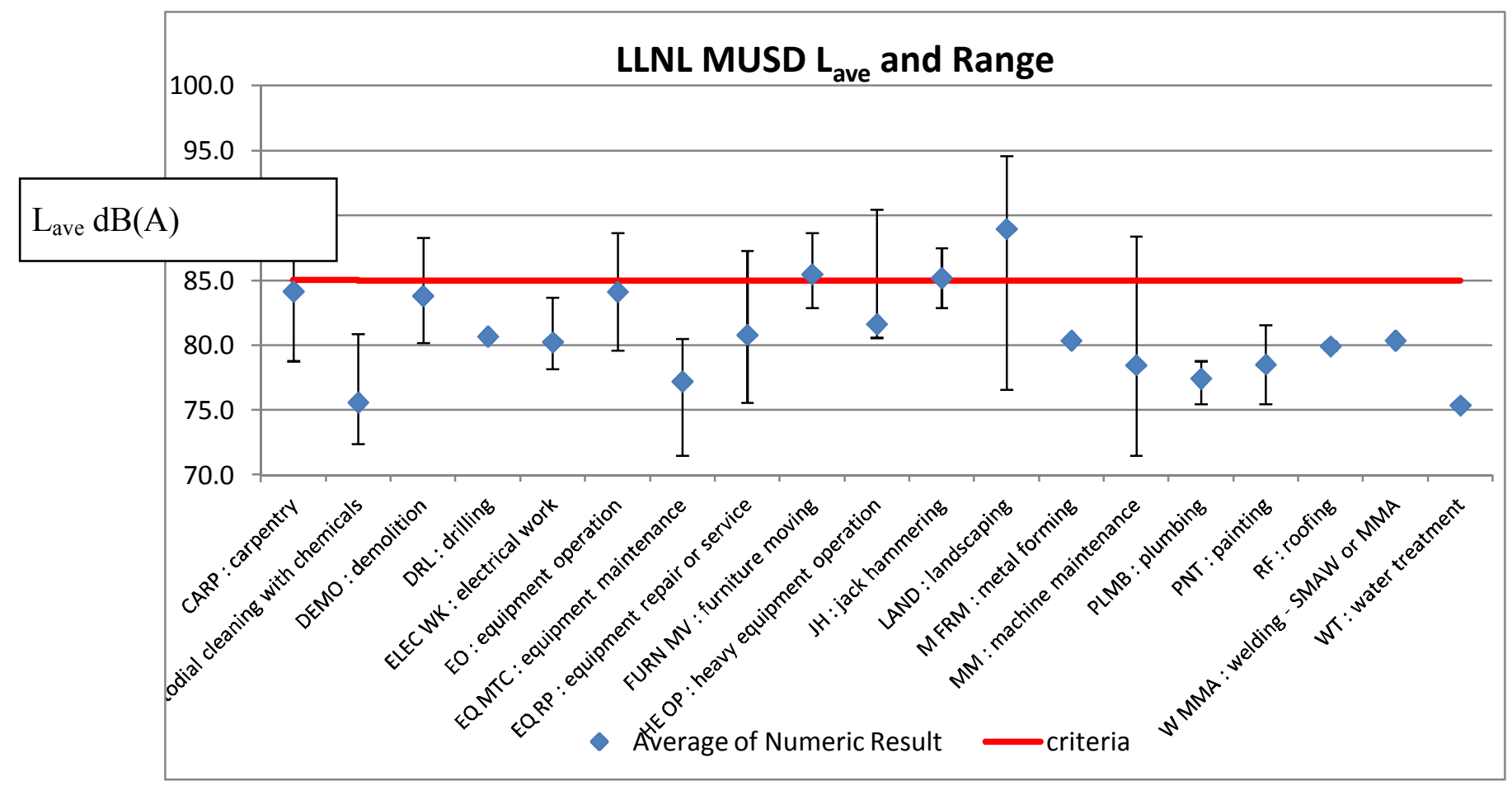

Notes:

- The Figure 2 criteria represents LLNL's adherence to ACGIH's TLV of $85 \mathrm{~dB}(\mathrm{~A})$.

- $\mathrm{L}_{\mathrm{ave}}$ and range values without regard to Hearing Protection Devices (HPDs). 
[Draft Report: Facility Maintenance Worker Noise Exposure Assessment Summary and Comparative Analysis]

MUSD Shop activities shown to generate noise resulting in worker exposures in excess of $85 \mathrm{~dB}(\mathrm{~A})$ are:

1. Machine Maintenance

2. Heavy Equipment Operation

3. Equipment Repair / Service

4. Carpentry, and

5. Landscaping

6. Demolition

7. Jack Hammering 


\section{Construction Industry Comparative Analysis}

As previously noted, the intent of this paper is to compare the findings of this Dosimetry assessment to data representative of the Construction Industry. Recent findings published by the Annals of Occupational Hygiene and the American Industrial Hygiene Association (AIHA) are available, informative, and relevant to construction Dosimetry similar to that conducted at LLNL ${ }^{7,8}$. The Annals of Occupational Hygiene findings follow construction worker cohort members from 1999 to 2009 during which, Dosimetry data were obtained including trade-mean noise level averages $\left(\mathrm{L}_{\mathrm{ave}}\right)$. Notable similarities between four trades of the cohort study and the LLNL data are shown in Table 2, Comparative Noise Dosimetry Summary. A statistical analysis of the values using the Wilcoxon Rank-Sum Test yields a statistic (W), providing a corresponding "p" value and a 95\% confidence level accepting a null hypothesis that the values are similar as shown in Attachment 3, Dosimetry Statistics.

Table 2

Comparative Noise Dosimetry Summary

\begin{tabular}{|l|c|c|c|}
\hline Trade SEG & $\begin{array}{c}\text { LLNL MUSD } \\
\left(\mathrm{L}_{\text {ave }}\right)\end{array}$ & $\begin{array}{c}\text { 10 Year Longitudinal } \\
\text { Cohort Study }^{\mathbf{1 0}} \\
\left(\mathrm{L}_{\text {ave }}\right)\end{array}$ & $\begin{array}{c}\text { Occupational } \\
\text { Assessment of Noise } \\
\text { Exposures }^{\mathbf{1 1}} \\
\left(\mathrm{L}_{\text {ave }}\right)\end{array}$ \\
\hline Carpenter & 84.2 & 83.7 & 80.3 \\
\hline Electrician & 80.3 & 80.4 & -- \\
\hline Operating Engineer & 84.2 & 84.1 & 84 \\
\hline Sheet Metal & 80.4 & 80.5 & -- \\
\hline $\begin{array}{l}\text { Construction / \# of } \\
\text { Samples (n) }\end{array}$ & $81.4 / 79$ & $82.6 / 1310$ & 39.7 \\
\hline $\begin{array}{c}\text { \% Overall } \\
\text { Construction Trades } \\
>\text { 85 dB(A) }\end{array}$ & 21.3 & 33.2 & \\
\hline
\end{tabular}

The findings of the AIHA Journal identify two (Carpenter and Operating Engineer) mean trade Dosimetry values also comparable to the LLNL MUSD assessment also shown in Table 2 


\section{Conclusions / Recommendations}

LLNL's MUSD Dosimetry assessment findings have documented worker exposures to hazardous levels (i.e. > ACGIH TLV of $85 \mathrm{~dB}(\mathrm{~A})$ ) of noise without regard to Hearing Protection Devices (HPDs). In addition, Dosimetry values are in general agreement with the Construction Industry as observed in the noted Longitudinal Cohort $\mathrm{Study}^{7}$, in particular, selected SEGs. Noise sources common to the excursions are those including hydraulics, pneumatics, and other energy intensive processes such as:

- Chop Saws

- Sheet Metal Shears

- Noisy tool

- Jack Hammers

- Circular Concrete Saws
- Table Saws

- Planers

- Mowers

- Stump Grinders

- Heavy Equipment

A notable observation from the Cohort Study illustrates minimal changes in full shift measured noise exposure over a 10 year period as shown in the figure below. This observation may be attributed to minimal improvements in noise source design within the industry.

Fig. 1.

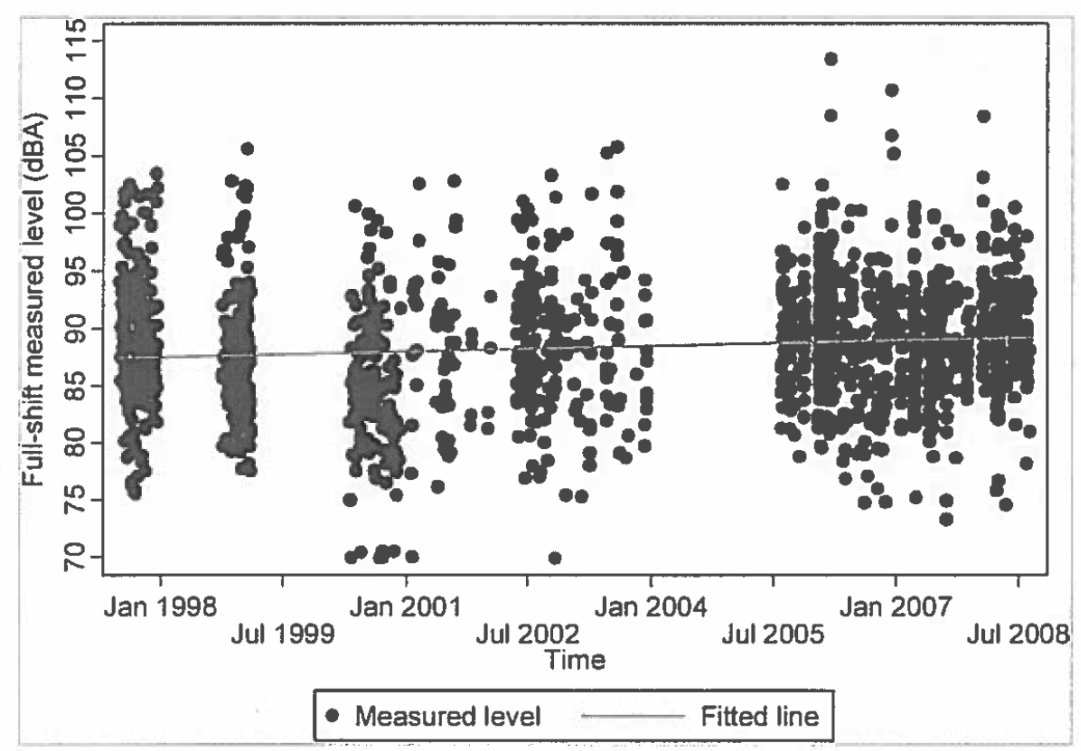

Full-shift dosimetry measurements over time $(n=1310$ measurements).

The Figure 1 above is presented with permisson ${ }^{7}$. 
The resultant worker exposures and presumed NIHL are likely to be a combination of:

- A lack of centralized Dosimetry data within the industry;

- A lack of centralized Medical Surveillance (audiometry);

- A need to improve worker training;

- A need to improve HPD compliance, and

- $\quad$ The need to develop and sustain a Hearing Conservation Program (HCP).

In a paper presented by Alice H. Suter ${ }^{1}$ the above issues are partially addressed and recommendations are made to utilize a credit card sized optical card storing useful information such as training and audiology available to transient Construction workers and their employers. 


\section{Table of Acronyms}

O\&M Operations and Maintenance

DOE

Department of Energy

OSHA Occupational Safety and Health Administration

NHCA National Hearing Conservation Association

CFR

$\mathrm{dB}(\mathrm{A})$

Code of Federal Regulations

$\mathrm{HCP}$

decibels (A Scale)

NIHL

Hearing Conservation Program

FOM

Noise Induced Hearing Loss

STS

Field Operations Manual

ACGIH

Standard Threshold Shift

TLV

$\mathrm{dB}$

American Conference of Governmental Industrial Hygienists

EPA

Threshold Limit Value

POD

Decibels

Environmental Protection Agency

SME

Plan of the Day

SEG

Subject Matter Expert

OTM

Similar Exposure Group

OBA

OSHA Technical Manual

Octave Band Analyzer 


\section{Attachment 1}

\section{MUSD Dosimetry data}




\begin{tabular}{|c|c|c|c|c|c|}
\hline & $\begin{array}{l}\text { Operation } \\
\text { Facility }\end{array}$ & Sample & $\begin{array}{l}\text { Process } \\
\text { Type }\end{array}$ & Task & $\begin{array}{l}\text { Numeric } \\
\text { Result }\end{array}$ \\
\hline 1 & B515 & 1005310 & MTC & LAND : landscaping & 94.6 \\
\hline 2 & B515 & 1005320 & MTC & LAND : landscaping & 92.9 \\
\hline 3 & B515 & 1005330 & MTC & LAND : landscaping & 91.9 \\
\hline 4 & B418 & 1002540 & MTC & HE OP : heavy equipment operation & 90.5 \\
\hline 5 & B418 & 1002550 & MTC & HE OP : heavy equipment operation & 89 \\
\hline 6 & B418 & 1002881 & MTC & EO : equipment operation & 88.7 \\
\hline 7 & B418 & 1002560 & MTC & FURN MV : furniture moving & 88.7 \\
\hline 8 & B519-R116 & 1004520 & MTC & MM : machine maintenance & 88.4 \\
\hline 9 & B418 & 1002560 & MTC & DEMO : demolition & 88.3 \\
\hline 10 & B418 & 1002520 & MTC & $\mathrm{JH}$ : jack hammering & 87.5 \\
\hline 11 & B511 & 1004360 & $\overline{M T C}$ & EQ RP : equipment repair or service & 87.3 \\
\hline 12 & B418 & 1003270 & MTC & HE OP : heavy equipment operation & 87.2 \\
\hline 13 & B511 & 1001940 & $\overline{\text { MTC }}$ & CARP : carpentry & 87 \\
\hline 14 & B511 & 1002270 & MTC & CARP : carpentry & 87 \\
\hline 15 & B418 & 1002870 & MTC & HE OP : heavy equipment operation & 87 \\
\hline 16 & B519 & 1004442 & MTC & HE OP : heavy equipment operation & 86.9 \\
\hline 17 & B418 & 1002271 & MTC & HE OP : heavy equipment operation & 86.8 \\
\hline 18 & B418 & 1002880 & MTC & HE OP : heavy equipment operation & 85 \\
\hline 19 & B418 & 1002570 & MTC & DEMO : demolition & 84.9 \\
\hline 20 & B418 & 1002570 & MTC & FURN MV : furniture moving & 84.9 \\
\hline 21 & B519-R116 & 1004456 & MTC & MM : machine maintenance & 84.7 \\
\hline 22 & B511 & 1001970 & MTC & CARP : carpentry & 84.6 \\
\hline 23 & B873 & 1004190 & MTC & HE OP : heavy equipment operation & 84.4 \\
\hline 24 & B511 & 1004641 & $\overline{M T C}$ & ELEC WK : electrical work & 83.7 \\
\hline 25 & B511 & 1002060 & MTC & CARP : carpentry & 83.5 \\
\hline 26 & B511 & 1004644 & MTC & ELEC WK : electrical work & 83.4 \\
\hline 27 & B418 & 1003260 & MTC & HE OP : heavy equipment operation & 83.4 \\
\hline 28 & B418 & 1002571 & MTC & FURN MV : furniture moving & 82.9 \\
\hline 29 & B418 & 1002571 & MTC & HE OP : heavy equipment operation & 82.9 \\
\hline 30 & B418 & 1002571 & $\overline{M T C}$ & $\mathrm{JH}$ : jack hammering & 82.9 \\
\hline
\end{tabular}

Notes

All units Average noise level, Decibels, A weighting scale $\mathrm{L}_{\mathrm{ave}}(\mathrm{dB}(\mathrm{A})$

Data available for comparison to Construction Industry Dosimetry 
[Draft Report: Facility Maintenance Worker Noise Exposure Assessment Summary and Comparative Analysis]

\begin{tabular}{|l|c|c|c|c|c|}
\hline & $\begin{array}{c}\text { Operation } \\
\text { Facility }\end{array}$ & $\begin{array}{c}\text { Sample } \\
\text { ID }\end{array}$ & $\begin{array}{c}\text { Process } \\
\text { Type }\end{array}$ & Task & $\begin{array}{c}\text { Numeric } \\
\text { Result }\end{array}$ \\
\hline
\end{tabular}

\begin{tabular}{|c|c|c|c|c|c|}
\hline 31 & B418 & 1003152 & MTC & HE OP : heavy equipment operation & 82.6 \\
\hline 32 & B418 & 1003160 & MTC & HE OP : heavy equipment operation & 82.2 \\
\hline 33 & B519-R116 & 1004454 & MTC & MM : machine maintenance & 82.1 \\
\hline 34 & B418 & 1002290 & MTC & DEMO : demolition & 81.9 \\
\hline 35 & B511 & 1004643 & MTC & ELEC WK : electrical work & 81.9 \\
\hline 36 & B519-R116 & 1004521 & MTC & MM : machine maintenance & 81.9 \\
\hline 37 & B517 & 1004772 & MTC & ELEC WK : electrical work & 81.6 \\
\hline 38 & B418 & 1002950 & MTC & PNT : painting & 81.6 \\
\hline 39 & B418 & 1002890 & MTC & HE OP : heavy equipment operation & 81.2 \\
\hline 40 & B511 & 1004562 & MTC & CCC : custodial cleaning with chemicals & 80.9 \\
\hline 41 & B511 & 1004270 & $\mathrm{C}$ & DRL : drilling & 80.7 \\
\hline 42 & B511 & 1004452 & MTC & ELEC WK : electrical work & 80.7 \\
\hline 43 & B519 & 1004440 & MTC & HE OP : heavy equipment operation & 80.6 \\
\hline 44 & B324 & 1006350 & MTC & EQ MTC : equipment maintenance & 80.5 \\
\hline 45 & B324 & 1005011 & MTC & EQ MTC : equipment maintenance & 80.4 \\
\hline 46 & B511 & 1004470 & MTC & M FRM : metal forming & 80.4 \\
\hline 47 & B511 & 1004470 & MTC & W MMA : welding - SMAW or MMA & 80.4 \\
\hline 48 & U291 & 1003310 & MTC & EQ MTC : equipment maintenance & 80.3 \\
\hline 49 & B511 & 1004130 & MTC & RF : roofing & 80.3 \\
\hline 50 & B418 & 1002307 & MTC & DEMO : demolition & 80.2 \\
\hline 51 & B324 & 1004972 & MTC & EQ MTC : equipment maintenance & 80.1 \\
\hline 52 & B517 & 1004770 & MTC & ELEC WK : electrical work & 79.9 \\
\hline 53 & B324 & 1005010 & MTC & EQ MTC : equipment maintenance & 79.8 \\
\hline 54 & B418 & 1002273 & MTC & EO : equipment operation & 79.6 \\
\hline 55 & B511 & 1004361 & MTC & EQ RP : equipment repair or service & 79.6 \\
\hline 56 & B511 & 1004120 & MTC & RF : roofing & 79.6 \\
\hline 57 & B511 & 1002260 & MTC & CARP : carpentry & 78.8 \\
\hline 58 & B511 & 1004350 & MTC & PLMB : plumbing & 78.8 \\
\hline 59 & B517 & 1004771 & MTC & ELEC WK : electrical work & 78.2 \\
\hline
\end{tabular}

Notes

All units Average noise level, Decibels, A weighting scale $\mathrm{L}_{\text {ave }}(\mathrm{dB}(\mathrm{A})$

Data available for comparison to Construction Industry Dosimetry 
[Draft Report: Facility Maintenance Worker Noise Exposure Assessment Summary and Comparative Analysis]

\begin{tabular}{|c|c|c|c|c|c|}
\hline & $\begin{array}{c}\text { Operation } \\
\text { Facility }\end{array}$ & $\begin{array}{c}\text { Sample } \\
\text { ID }\end{array}$ & $\begin{array}{c}\text { Process } \\
\text { Type }\end{array}$ & Task & $\begin{array}{c}\text { Numeric } \\
\text { Result }\end{array}$ \\
\hline
\end{tabular}

\begin{tabular}{|c|c|c|c|c|c|}
\hline 60 & B511-R110 & 1004873 & MTC & MM : machine maintenance & 78.1 \\
\hline 61 & B511 & 1003901 & MTC & PLMB : plumbing & 78.1 \\
\hline 62 & B511 & 1004451 & MTC & ELEC WK : electrical work & 78 \\
\hline 63 & B515 & 1005311 & MTC & LAND : landscaping & 76.6 \\
\hline 64 & B511 & 1004262 & $\mathrm{C}$ & EQ RP : equipment repair or service & 75.6 \\
\hline 65 & B511 & 1004430 & MTC & MM : machine maintenance & 75.6 \\
\hline 66 & B511 & 1004351 & MTC & PLMB : plumbing & 75.5 \\
\hline 67 & B418 & 1001950 & MTC & PNT : painting & 75.5 \\
\hline 68 & U291 & 1003330 & MTC & WT : water treatment & 75.4 \\
\hline 69 & B511 & 1004560 & MTC & CCC : custodial cleaning with chemicals & 75.2 \\
\hline 70 & B324 & 1006290 & MTC & EQ MTC : equipment maintenance & 75.2 \\
\hline 71 & B511 & 1004453 & MTC & ELEC WK : electrical work & 75.1 \\
\hline 72 & B324 & 1004971 & MTC & EQ MTC : equipment maintenance & 74.2 \\
\hline 73 & B511 & 1004561 & MTC & CCC : custodial cleaning with chemicals & 74 \\
\hline 74 & B324 & 1004970 & MTC & EQ MTC : equipment maintenance & 72.9 \\
\hline 75 & B511-R110 & 1004871 & MTC & MM : machine maintenance & 72.6 \\
\hline 76 & B519 & 1004441 & MTC & CCC : custodial cleaning with chemicals & 72.4 \\
\hline 77 & B324 & 1005140 & MTC & EQ MTC : equipment maintenance & 71.8 \\
\hline 78 & B511 & 1004431 & MTC & MM : machine maintenance & 71.6 \\
\hline 79 & B511-R110 & 1004870 & MTC & MM : machine maintenance & 71.50 \\
\hline & & & & Av & 81.43 \\
\hline
\end{tabular}

Notes

All units Average noise level, Decibels, A weighting scale $\mathrm{L}_{\mathrm{ave}}(\mathrm{dB}(\mathrm{A})$

Data available for comparison to Construction Industry Dosimetry 


\section{Attachment 2}

\section{Dosimetry Statistics}




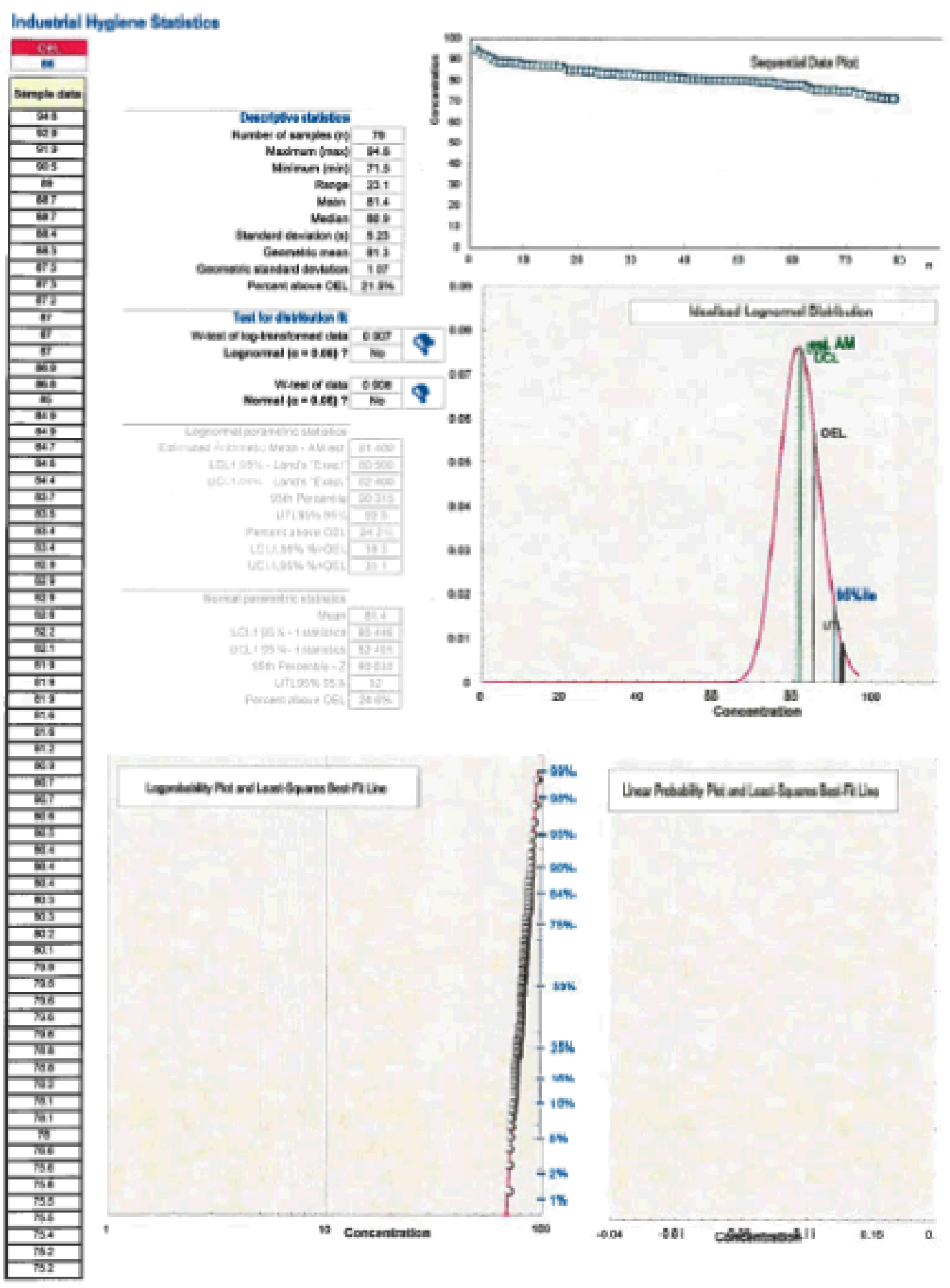


[Draft Report: Facility Maintenance Worker Noise Exposure Assessment Summary and Comparative Analysis]

\section{The Wilcoxon Rank-Sum Test (Two Independent Samples)}

\begin{tabular}{|c|c|c|}
\hline & 83.7 & 84.2 \\
\hline Observations: & 4 & 4 \\
\hline Mean: & 81.9 & 82.625 \\
\hline Median: & 81.55 & 82.3 \\
\hline Standard Deviation: & 1.783255 & 2.688711 \\
\hline \multicolumn{3}{|l|}{ The Test Procedure } \\
\hline Hypothetical Mean Difference: & \multicolumn{2}{|l|}{0} \\
\hline Nb. of Tie Series: & \multicolumn{2}{|l|}{7} \\
\hline Average Nb. of Tie per Series: & \multicolumn{2}{|l|}{1.142857} \\
\hline Rank Sum: & \multicolumn{2}{|l|}{36} \\
\hline Rank Average: & \multicolumn{2}{|l|}{4.5} \\
\hline Test Statistic (W): & \multicolumn{2}{|l|}{17.5} \\
\hline Nominal Significance Level: & \multicolumn{2}{|l|}{0.05} \\
\hline Actual Signif. Lev.: & \multicolumn{2}{|l|}{0.014286} \\
\hline \multicolumn{3}{|l|}{ Exact Procedure Two-Tailed Test } \\
\hline Critical Values: & \multicolumn{2}{|l|}{10 and 26} \\
\hline Decision Rule: & \multicolumn{2}{|c|}{ Reject $\mathrm{HO}$ if $\mathrm{W}<10$, or $\mathrm{W}>26$} \\
\hline Final Decision: & \multicolumn{2}{|c|}{$\begin{array}{l}\text { The Null Hypothesis Cannot be Rejected } \\
\text { due to Insufficient Evidence in the Sample }\end{array}$} \\
\hline P-Value: & \multicolumn{2}{|l|}{0.885714} \\
\hline
\end{tabular}

\begin{tabular}{|l|c|c|c|c|}
\multicolumn{1}{c|}{} & INPUT DATA \& RANKS \\
\cline { 2 - 5 } \multicolumn{1}{c|}{} & Cohort & MUSD & \multicolumn{2}{c|}{ RANKS } \\
\hline Carpenters & 83.7 & 84.2 & 83.7 & 84.2 \\
\hline Electricians & 80.4 & 80.3 & 2.5 & 1 \\
\hline $\begin{array}{l}\text { Equipment } \\
\text { Operation }\end{array}$ & 84.1 & 84.2 & 6 & 7 \\
\hline Sheet Metal & 80.5 & 80.4 & 4 & 2.5 \\
\hline Construction & 82.6 & 81.43 & 5 & 8 \\
\hline
\end{tabular}




\section{Appendix 1}

Noise Dosimetry Record 
[Draft Report: Facility Maintenance Worker Noise Exposure Assessment Summary and Comparative Analysis]

November 18, 2013

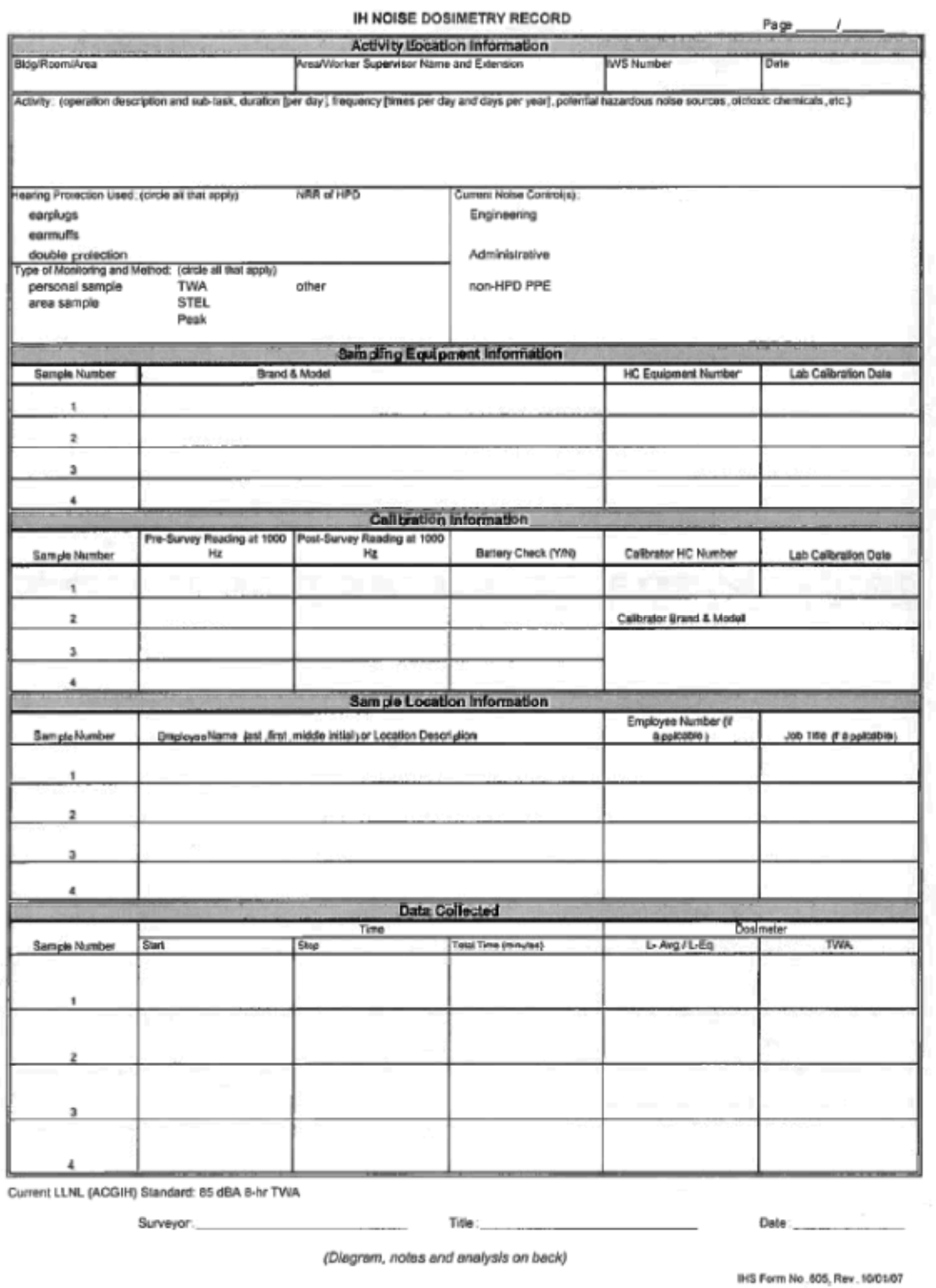


IH NOISE DOSIMETRY RECORO

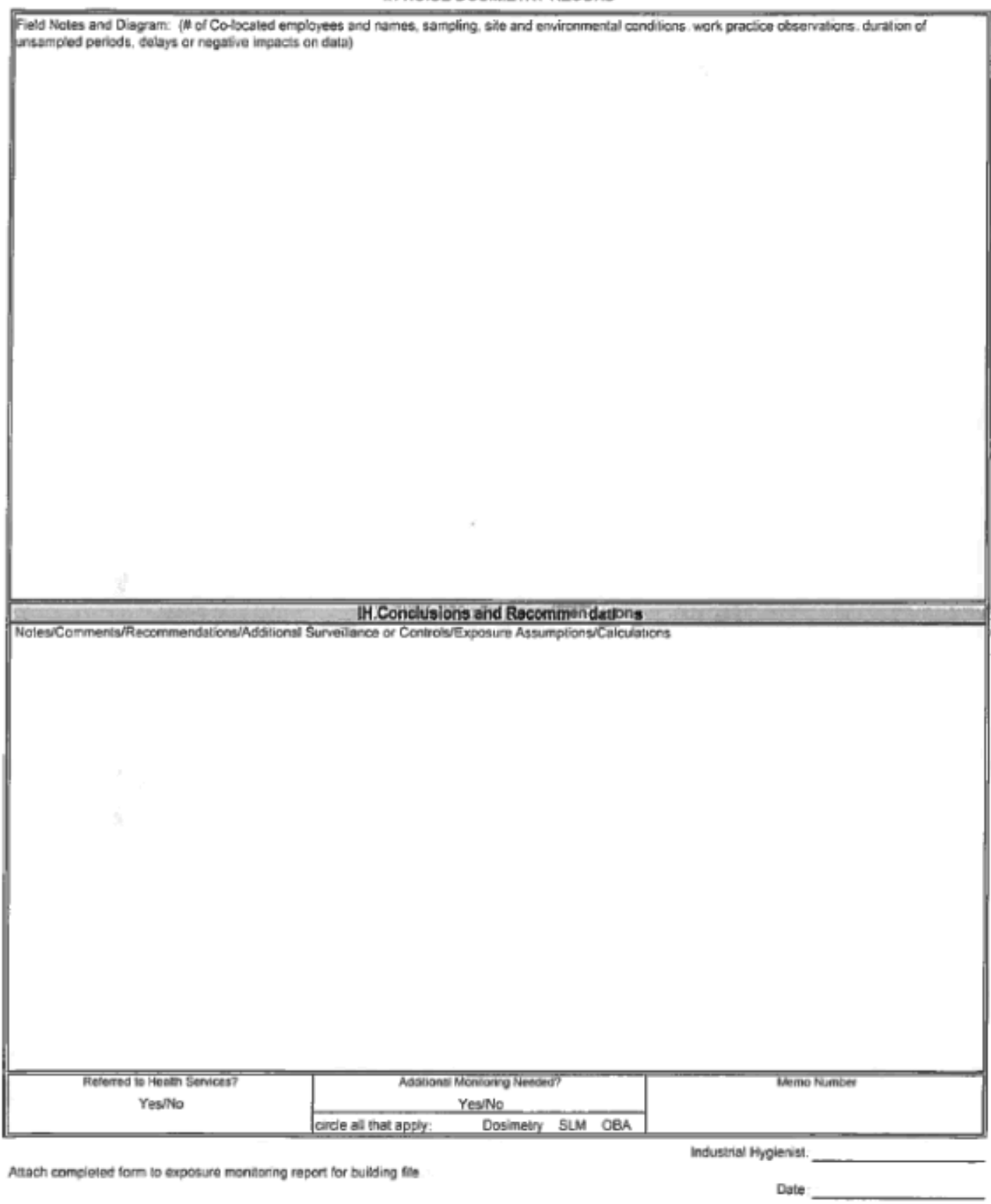

Lvelink file location

HS Form Na 605, Rer 100100 
[Draft Report: Facility Maintenance Worker Noise Exposure Assessment Summary and Comparative Analysis]

IH SOUND LEVEL IOCTAVE BAND ANALYSIS RECORD Page ' Activity Location Information

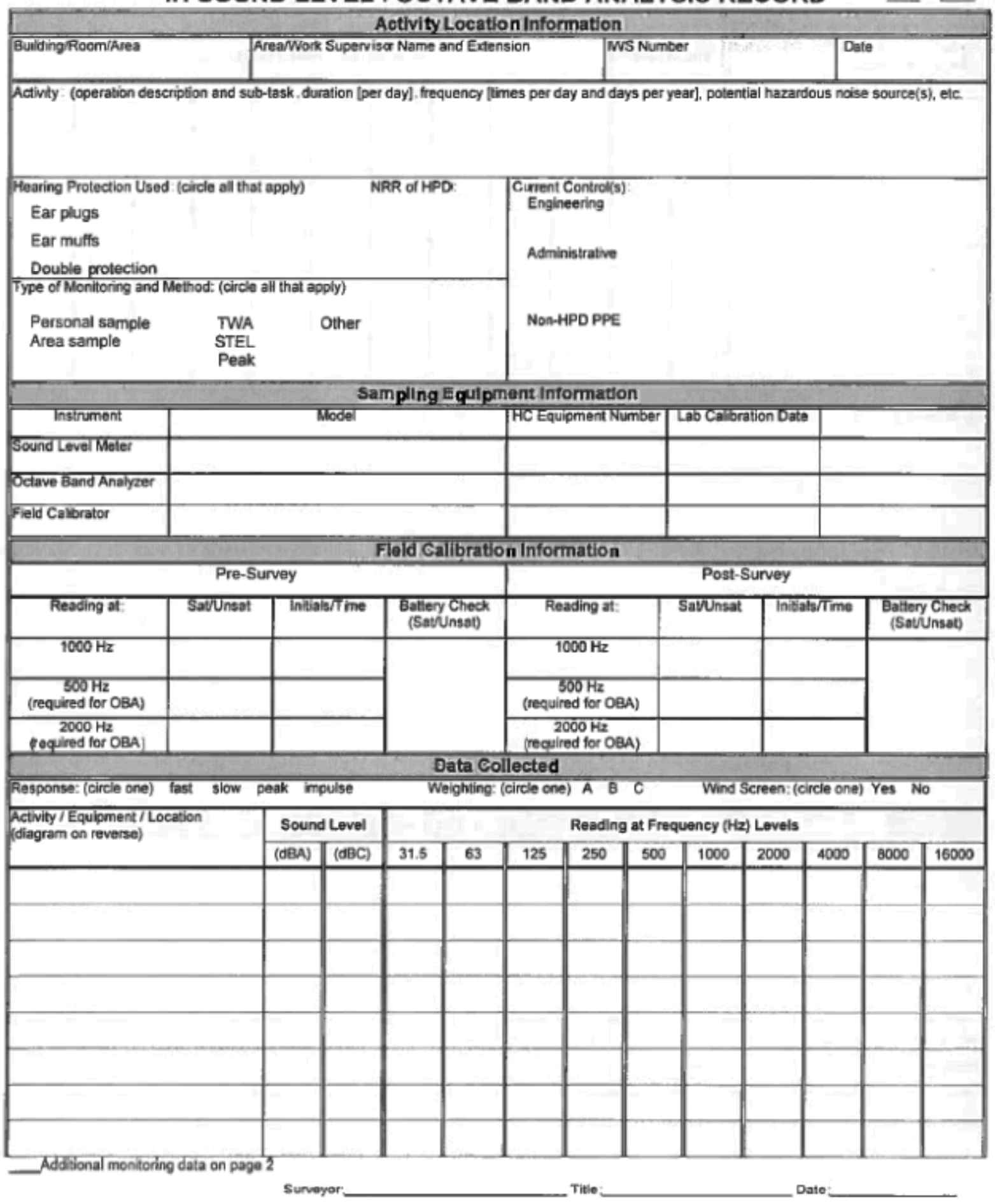

IH . Forms, Rev 3 , Dec 2007

(Diagram, notes and analysis on back) 
[Draft Report: Facility Maintenance Worker Noise Exposure Assessment Summary and Comparative Analysis]

\begin{tabular}{|l|c|c|c|c|c|c|c|c|c|c|c|c|}
\hline \hline & Data Collocted cont. \\
\hline $\begin{array}{l}\text { Operation / Equipment } \\
\text { (diagram on feverse) }\end{array}$ & Sound Lovel & \multicolumn{1}{|c|}{ Reading at Frequency (Hz) Levels } \\
\hline & (dBA) & (dBC) & 31.5 & 63 & 125 & 250 & 500 & 1000 & 2000 & 4000 & 8000 & 16000 \\
\hline & & & & & & & & & & & & \\
\hline & & & & & & & & & & & & \\
\hline & & & & & & & & & & & & \\
\hline & & & & & & & & & & & & \\
\hline & & & & & & & & & & & & \\
\hline & & & & & & & & & & & & \\
\hline
\end{tabular}

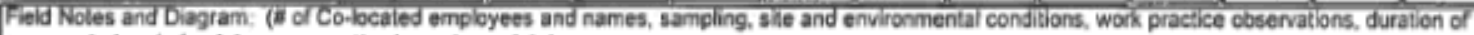
un-sampled periods. delays or negative impacts on data)

\section{IHConclusions and Recommendations}

Notes/Comments/Recormmendations/Adddional Surveilance or Controis/Exposure Assumptions/Calculations

\begin{tabular}{|c|c|c|c|c|c|c|}
\hline \multicolumn{2}{|c|}{ Additional Monitoring Needed? } & \multicolumn{2}{|l|}{$\mathrm{Y} / \mathrm{N}$} & \multirow{2}{*}{\multicolumn{2}{|c|}{$\begin{array}{l}\text { Hearing Protection Recommended } \quad \mathrm{Y} / \mathrm{N} \\
\text { Type }\end{array}$}} & \multirow[t]{2}{*}{ Merno Number } \\
\hline Circie al that apply. & Dosimetry & SLM & OBA & & & \\
\hline
\end{tabular}

Altach completed form to exposure monitoring report for building file

Industrial Hygienist:

Date:

Livelink file location: 


\section{References}

${ }^{1}$ Suter A. H. (2002). Construction Noise: Exposure, Effects, and the Potential for Remediation: A Review and Analysis. AIHA Journal 63:768-789

${ }^{2}$ OSHA Docket Office. Feasible Noise Control. Constitution Avenue, NW, Washington, DC 20210: Docket No. OSHA-2010-0032,

${ }^{3}$ OSHA Quick Takes, Section II: What standards limit and control noise exposure?, Construction Industry, Hearing Conservation Program

${ }^{4}$ U.S. Department of Labor, Occupational Safety and Health Administration, OSHA Technical Manual, Chapter 5, Noise and Hearing Conservation

${ }^{5}$ U.S. Environmental Protection Agency, EPA Guidance for Quality Assurance Project Plans. EPA QA/G-5

${ }^{6}$ Guidance on Systematic Planning Using The Data Quality Objectives Process EPA QA/G4

${ }^{7}$ Richard. L. Neitzel, Bert. Stover, and Noah. S. Seixas. Longitudinal Assessment of Noise Exposure in a Cohort of Construction Workers. Ann Occup Hyg. 2011 Oct, 55 (8): 906-916.

${ }^{8}$ Richard L. Neitzel, Noah S. Seixas, Janice Camp, Michael Yost. An Assessment of Occupational Noise Exposures in Four Construction Trades. AIHA Journal (60). November/December 1999.

\section{Acknowledgments}

George P. Fulton, MS Chemistry, CIH

LLNL IH Section SME 